\title{
Basic Fibroblast Growth Factor Induces Angiogenic Properties of Fibrocytes to Stimulate Vascular Formation during Wound Healing
}

\author{
Miho Nakamichi, ${ }^{*}$ Yuri Akishima-Fukasawa, ${ }^{\dagger}$ Chie Fujisawa, ${ }^{\dagger}$ Tetuo Mikami, ${ }^{\dagger}$ Kiyoshi Onishi, ${ }^{*}$ and Yoshikiyo Akasaka ${ }^{\dagger \S}$
}

\begin{abstract}
From the Department of Plastic and Reconstructive Surgery, ${ }^{*}$ Toho University Omori Medical Center, Tokyo; and the Department of Pathology, ${ }^{\dagger}$ School of Medicine, and the Division of Research Promotion and Development $t^{\ddagger}$ and the Regenerative Disease Research Unit, ${ }^{\S}$ Advanced Research Center, Toho University, Tokyo, Japan
\end{abstract}

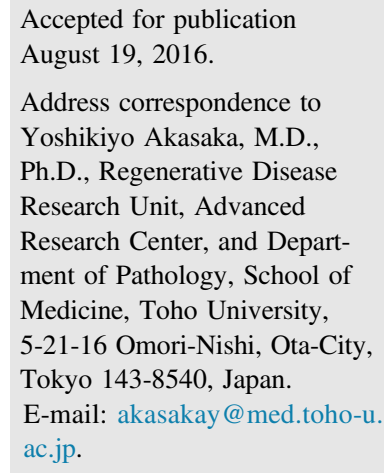

\begin{abstract}
The role of fibrocytes in wound angiogenesis remains unclear. We therefore demonstrated the specific changes in fibrocyte accumulation for angiogesis in basic fibroblast growth factor (bFGF)-treated wounds. bFGF-treated wounds exhibited marked formation of arterioles and inhibition of podoplanin ${ }^{+}$lymph vessels that were lacking in vascular endothelial growth factor-A-treated wounds. Real-time PCR in bFGF-treated wounds manifested enhanced expression of CD34, CD31, and bFGF mRNA and reduced expression of podoplanin and collagen type I, III, and IV mRNA. Double immunofluorescence staining focusing on fibrocyte detection in bFGF-treated wounds showed increased formation of capillary-like structures composed of $\mathrm{CD}_{3} 4^{+} /$procollagen $\mathrm{I}^{+}$fibrocytes, with a lack of capillary-like structures formed by $\mathrm{CD}_{4} 5^{+} /$procollagen $\mathrm{I}^{+}$or $\mathrm{CD}_{11} \mathrm{~b}^{+} /$procollagen $\mathrm{I}^{+}$fibrocytes. However, vascular endothelial growth factor-A-treated wounds lacked capillary-like structures composed of $\mathrm{CD} 34^{+} / \mathrm{pro}^{-}$ collagen $\mathrm{I}^{+}$fibrocytes, with increased numbers of ${\mathrm{CD} 34^{+}}^{+}$fetal liver kinase- $1^{+}$endothelial progenitor cells. Furthermore, fibroblast growth factor receptor 1 siRNA injection into wounds, followed by bFGF, inhibited the formation of capillary-like structures composed of $\mathrm{CD}_{3} 4^{+} /$procollagen $\mathrm{I}^{+}$fibrocytes, together with inhibited mRNA expression of CD34 and CD31 and enhanced mRNA expression of collagen type I, indicating the requirements of bFGF/fibroblast growth factor receptor 1 system for capillary structure formation. This study highlights the angiogenic properties of $\mathrm{CD}_{3} 4^{+} /$procollagen $\mathrm{I}^{+}$fibrocytes specifically induced by bFGF, providing new insight into the active contribution of fibrocytes for vascular formation during wound healing. (Am J Pathol 2016, 186: 3203-3216; http://dx.doi.org/ 10.1016/j.ajpath.2016.08.015)
\end{abstract}

Wound healing is a complex process, and the mechanisms underlying granulation tissue formation remain obscure. Among the types of granulation tissue cells, fibroblasts have distinctive functions and have been postulated to partly originate from peripheral blood cells. Numerous studies have explored the pathways by which peripheral mononuclear cells undergo differentiation into fibroblasts.

A distinct population of bone marrow-derived cells with fibroblast-like properties was described by Bucala et $\mathrm{al}^{1}$ that were termed fibrocytes and account for $0.1 \%$ to $0.5 \%$ of circulating leukocytes in the peripheral blood. Cultured fibrocytes display coexpression of a hematopoietic stem cell marker (CD34), leukocyte common antigen (CD45), monocyte lineage markers, such as CD11b, CD13, and major histocompatibility complex class II, and fibroblastic markers, such as collagens I, III, and IV, procollagen I, and fibronectin. ${ }^{1-5}$ These cells also secrete proinflammatory cytokines, such as tumor necrosis factor, matrix metalloproteinase-9, IL-6, IL-8, and IL-10, ${ }^{1-5}$ and express various chemokine receptors, such as CCR7 and chemokine receptor type 4 , that regulate recruitment of inflammatory

\footnotetext{
Supported by Japanese Society for the Promotion of Science KAKENHI grants JP25462804 and 26460480 and Strategic Research Foundation grant-aided Project for Private Schools at Heisei $23^{\text {rd }}$ grant S1101016 from the Ministry of Education, Culture, Sports, Science and Technology of Japan 2011-2015.

Disclosures: None declared.
} 
cells. $^{6-9}$ Based on these findings, fibrocytes have been assumed to play a pivotal role in both wound healing ${ }^{10-12}$ and the development of tissue fibrosis in certain fibrotic diseases. ${ }^{9,13-17}$ During the process of tissue fibrosis, fibrocytes have been speculated to infiltrate the extravascular tissues and differentiate into myofibroblasts, leading to collagen production and subsequent fibrosis. ${ }^{2,18}$ However, the mechanisms underlying granulation tissue formation mediated by fibrocytes in wounds, especially those underlying the role of fibrocytes in angiogenesis, remain obscure.

Recent accumulating evidence suggested that fibrocytes could play an important role in angiogenesis, because in vitro evidence indicated that fibrocytes express high levels of angiogenetic growth factors, such as vascular endothelial growth factor (VEGF), basic fibroblast growth factor (bFGF), and platelet-derived growth factor. ${ }^{5}$ Further investigations provided supporting evidence for an angiogenic role of fibrocytes, by demonstrating that the culture medium of fibrocytes promoted angiogenesis in vitro and in vivo. ${ }^{19,20}$ These combined findings indicate that fibrocytes can act as a positive regulator of angiogenesis. However, a recent investigation demonstrated that fibrocytes can also play a role as a negative regulator of angiogenesis, because certain types of fibrocytes secrete angiogenesis inhibitors. ${ }^{21}$ Therefore, the angiogenetic properties of fibrocytes and the role of specific subtypes of fibrocytes in angiogenesis during wound healing need to be clarified.

The growth factor bFGF plays a role as a potent inducer of angiogenesis because it can enhance mitogenesis of endothelial cells. bFGF is also a positive regulator of angiogenesis by recruitment of inflammatory cells, such as monocytes, macrophages, and neutrophils, as a result of its up-regulation of the expression of various chemokines, such as chemokine (C-C motif) ligands 2 and 7 and CXCL1. ${ }^{22}$ VEGF-A is an important growth factor for promotion of the early events of angiogenesis, particularly for the promotion of endothelial cell migration. ${ }^{23}$ Therefore, the contribution of bFGF to fibrocyte recruitment during the process of angiogenesis needs to be investigated. Our aim was to examine the role of fibrocytes in angiogenesis in wound healing and then to clarify the mechanisms by which bFGF promotes angiogenesis in wounds and how such mechanisms might involve angiogenic properties of fibrocytes.

\section{Materials and Methods}

\section{Animals}

All experimental studies were approved by Toho University Laboratory Animal Research Committee (authorization number 15-33-239), complied with the Guidelines on Animal Experiments of Toho University in accordance with the Japanese Government Animal Protection and Management Law (number 105), and conformed to the European Union
Directive 2010/63/EU for Animal Experiments. Male Sprague-Dawley rats were purchased from CLEA Japan, Inc. (Tokyo, Japan) and were acclimatized in our laboratory for $\geq 7$ days before use.

\section{Skin Wounding}

Sprague-Dawley rats were anesthetized with isoflurane (WAKO Pure Chemical Industries, Ltd, Osaka, Japan) at a concentration of $3 \%$ in oxygen, using a precision vaporizer (TK-7; Bio Machinery Co Ltd, Chiba, Japan). The following four treatment groups were established: a control group and a bFGF group in which phosphate-buffered saline (PBS) and $10 \mathrm{ng}$ of bFGF (100 ng/mL; Kaken Pharmaceutical Co Ltd, Tokyo, Japan), respectively, were applied onto full-thickness wounds. The last two groups were a control group and a VEGF-A (Peprotech, Rocky Hill, NJ) group, in which PBS and $1 \mu \mathrm{g}$ of VEGF-A, respectively, were applied onto full-thickness wounds. A total of 20 male Sprague-Dawley rats (body weight, 390 to $400 \mathrm{~g}$ ) were used for this study. The rats were randomly assigned to one of the four groups before surgery, and the groups were evaluated on days $2,4,6,7$, and 14 postoperatively. Before incision, the back was clipped and disinfected with Hibitane (5\% chlorhexidine gluconate; AstraZeneca Pharmaceutical Co, Osaka, Japan) containing alcohol. For each rat, four fullthickness wounds (10 $\mathrm{mm}$ in diameter) composed of two bFGF-treated wounds and two PBS-treated wounds or two VEGF-A-treated wounds and two PBS-treated wounds were generated on the dorsal skin using a biopsy punch (Kai Industries Co, Ltd, Gifu, Japan). After the generation of fullthickness wounds at 2-cm intervals, a bFGF- or VEGFA-treated artificial dermis (Pelnac; Gunze Corp., Osaka, Japan) was prepared by dropping $0.1 \mathrm{~mL}$ of PBS containing bFGF or VEGF-A onto the artificial dermis (Figure 1A). The full-thickness wounds were then treated with the artificial dermis that had been immersed in bFGF or VEGF-A.

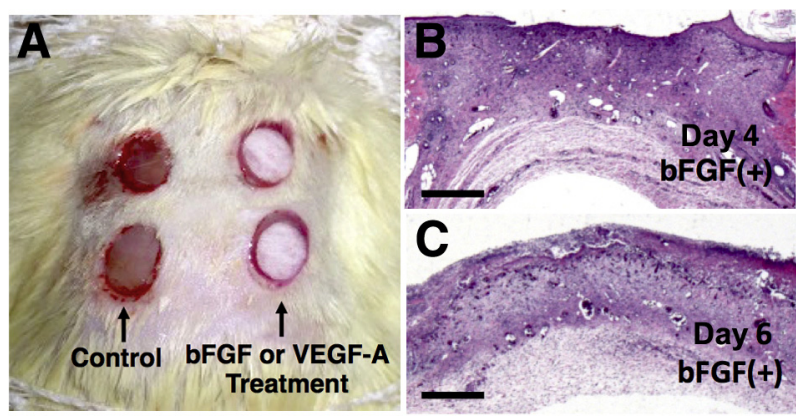

Figure 1 Full-thickness wounds in the dorsal skin of Sprague-Dawley rats. A: Four full-thickness wounds, a diameter of $10 \mathrm{~mm}$, were generated in the dorsal skin of Sprague-Dawley rats using a biopsy punch. Two wounds on the right side were treated with the artificial dermis that had been immersed in basic fibroblast growth factor (bFGF) or vascular endothelial growth factor (VEGF)-A. B and C: Histology of transverse sections of bFGF-treated $[\mathrm{bFGF}(+)]$ wounds on days $4(\mathbf{B})$ and $6(\mathbf{C})$ after operation. Hematoxylin and eosin staining was used. Scale bars $=500 \mu \mathrm{m}$ (B and C). 
To protect against dehydration and infection, wounds were covered with occlusive polyurethane foam dressings (Hydrosite plus; Smith \& Nephew Wound Management KK, Tokyo, Japan) that were fixed using nylon sutures (A18-40N3; Natsume Seisakusho, Tokyo, Japan). Each treatment was assigned to a different position on the dorsal skin to eliminate any effect of wound placement. Groups of rats received in the animal-euthanizing chambers were euthanized by using carbon dioxide fed from a gas feeder (KN-750-2-A; Natsume Seisakusho) on days 2, 4, 6, 7, and 14 postoperatively, with a total of 16 wounds (four bFGFtreated wounds and four PBS-treated wounds or four VEGF-treated wounds and four PBS-treated wounds) obtained on each day. For the following examination, the wound and surrounding tissue, including the entire wound bed, were excised. Excised tissue samples were then cut into two pieces. One piece was fixed in buffered $4 \%$ paraformaldehyde for histologic examination and embedded in paraffin, according to standard protocols (Figure 1, B and $\mathrm{C}$ ). Another piece was excised for RNA extraction and was stored at $-20^{\circ} \mathrm{C}$ in a deep freezer.

\section{Histologic Analysis}

Histologic analysis was performed according to methods described previously. ${ }^{24}$ Briefly, for identification of four different histologic types of vessels (capillaries, arterioles, arteries, and lymph vessels), horizontal sections of the wound granulation tissue stained by the triple immunohistochemical staining method described below were scanned using ImageJ software version 1.41 (NIH, Bethesda, MD; http://imagej.nih.gov/ij), and the digital images were analyzed. Three unbiased observers (Y.A.-F., T.M., and K.O.) randomly selected 10 fields in granulation tissues per tissue section. In each field, they counted the number of four types of vessels (capillaries, arterioles, arteries, and lymph vessels) at $\times 80$ magnification, and the average number of each type of vessel per field was finally calculated as the density of each type of vessel.

For counting of fibrocytes, the three observers also assessed the number of double-positive fibrocytes. Ten to twelve randomly selected fields in granulation tissues per tissue section were examined, and the numbers of doublepositive fibrocytes were counted and calculated as the mean number of positively stained cells per total number of DAPI-positive granulation tissue cells at $\times 80$ magnification.

We conducted immunohistochemical staining for counting the numbers of vessels using von Willebrand factor (vWF) antibody, as described previously. ${ }^{25,26}$ The primary antibody was a rabbit anti-vWF antibody at a dilution of 1:100 that had been purchased from Abcam, Inc. (ab6994; Cambridge, MA). The secondary antibody/reagent was Envision $^{+}$mouse peroxidase detection system that had been purchased from Dako (K4001; Glostrup, Denmark).

We conducted triple immunohistochemical staining for identification of four different types of vessels (capillaries, arterioles, arteries, and lymph vessels) using anti-CD34, anti- $\alpha$-smooth muscle actin ( $\alpha$-SMA), and anti-podoplanin antibodies. Sections were heated to $95^{\circ} \mathrm{C}$ for 5 minutes in a jar with an antigen activation solution at $\mathrm{pH} 9$ (Nichirei Corp., Tokyo, Japan) and were then incubated with rabbit anti-CD34 (ab150060; Abcam, Inc.) and mouse antipodoplanin antibodies (D2-40) (NB120-11842; Novus Biologicals, Littleton, CO) at dilutions both of 1:100. The sections were washed with Tris-buffered saline containing $0.05 \%$ Tween 20 , incubated with anti-rabbit alkaline phosphatase-conjugated secondary antibodies (Nichirei Corp.) at a dilution of 1:100, and further incubated with the New Fuchsin substrate solution (Nichirei Corp.). After washing with Tris-buffered saline containing $0.05 \%$ Tween 20 , the sections were incubated with biotin-conjugated secondary antibodies directed against mouse (BA2000; Vector Laboratories, Burlingame, $\mathrm{CA}$ ) and with streptavidin conjugated to horseradish peroxidase (Nichirei Corp.) at dilutions both of 1:100 and were further incubated with the Deep Space Black Chromogen Kit (Biocare Medical, Concord, CA). After washing with Tris-buffered saline containing $0.05 \%$ Tween 20, the sections were incubated with a mouse anti- $\alpha$-SMA antibody, followed by a streptavidin-biotinperoxidase complex (U7033; Dako) at dilutions both of 1:100 and staining with 3,3'-diaminobenzidine (Dako).

We conducted double immunofluorescence (IF) staining for identification of fibrocytes, as described previously. ${ }^{10,20}$ The primary antibodies were as follows: a rabbit anti-CD34 antibody (ab150060) at a dilution of 1:100, a rabbit antiCD45 antibody (ab10558) at a dilution of 1:100, a rabbit anti-CD11b antibody (ab75476) at a dilution of 1:200, and a mouse anti-fibroblast growth factor receptor 1 (FGFR1) antibody (ab829) at a dilution of 1:100, which were all purchased from Abcam, Inc. A goat anti-procollagen I antibody (sc25973) at a dilution of 1:100 was purchased from Santa Cruz Biotechnology, Inc. (Dallas, TX). The secondary antibodies used were as follows: biotinconjugated secondary antibodies directed against goat (BA9500), biotin-conjugated secondary antibodies directed against mouse (BA2000), Texas Red avidin D (A2006), Texas Red anti-goat IgG antibody (TI-5000), and fluorescein avidin D (A2001), which had been all purchased from Vector Laboratories. Fluorescein isothiocyanate-conjugated anti-rabbit immunoglobulins (F0205) were purchased from Dako. Negative controls were generated by incubating tissue sections (bFGF-treated wounds on day 6) with Ig from the same species [goat Ig (I-5000; Vector Laboratories) and rabbit Ig (I-1000; Vector Laboratories)] at the same final concentration, but with no primary antibody. Unstained controls were generated by incubating tissue sections (bFGF-treated wounds on day 6) with PBS, but with no primary antibody.

For identification of endothelial progenitor cells, double IF staining was performed as described previously. ${ }^{27}$ The primary antibodies were as follows: a rabbit anti-CD34 antibody (ab150060; Abcam, Inc.) at a dilution of 1:100 
and a mouse anti-fetal liver kinase (Flk)-1 antibody (sc393163; Santa Cruz Biotechnology, Inc.) at a dilution of 1:100. The secondary antibodies used were as follows: biotin-conjugated secondary antibodies directed against mouse (BA2000) were purchased from Vector Laboratories. Fluorescein isothiocyanate-conjugated swine anti-rabbit immunoglobulins (F0205) and Texas Red avidin D (A2006) were purchased from Dako and Vector Laboratories, respectively.

Cellular colocalization was evaluated using Graphic Converter Universal Binary software version 6.1.2J (Lemke Software GmbH, Peine, Germany).

\section{RNA Interference}

siRNA targeting the human and rat FGFR1 mRNA (http:// www.ncbi.nlm.nih.gov/nuccore/D12498.1; accession number D12498.1) was designed and synthesized by Nippon Gene Co, Ltd (Toyama, Japan). The siRNA sense strand sequence was as follows: CCAAUGAGCUGUACAUGAUdTdT. As a negative control, control siRNA (scrambled siRNA; sc37007) was purchased from Santa Cruz Biotechnology, Inc. The synthesized siRNAs were dissolved in TransIT-QR hydrodynamic delivery solution (Mirus Bio LCC, Madison, WI), which also served as control, and were injected into rat skin. The rats were dosed with a single intradermal injection of $20 \mu \mathrm{g}$ of siRNA (siFGFR1 group) or control siRNA (siCON group) per rat, three times at intervals of 2 days, with two rats in each group. bFGF treatment after siRNA injection was performed as follows. At 24 hours after the last injection, full-thickness wounds $10 \mathrm{~mm}$ in diameter were generated on the siRNAinjected sites using a biopsy punch (Kai Industries Co, Ltd). After the generation of full-thickness wounds that had been injected with siRNA (siFGFR1 group) or control siRNA (siCON group), the full-thickness wounds were treated with the bFGF-treated artificial dermis (Pelnac), as described above. At 2, 4, 6, 7, and 14 days after bFGF treatment, skin tissue samples were excised from the wounds and were cut into two pieces, one for immunohistochemistry and one for PCR analysis.

\section{RNA Isolation and Quantitative RT-PCR}

Tissue samples excised from wounds were homogenized in FastPrep-24 (MP Biomedicals, Solon, OH), and the RNA was isolated using NucleoSpin RNA (Macherey-Nagel, Düren, Germany) and then reverse transcribed using the PrimeScript RT Reagent Kit (Takara Bio Inc., Kyoto, Japan). Target gene expression was estimated using TaqMan gene expression assays specific for CD34 (Rn03416140), CD31 (Rn01467262), podoplanin (Rn01637526), bFGF (Rn00570809), FGFR1 (Rn01478647), and $\beta$-actin (Rn01759928) (Applied Biosystems, Foster, CA). ${ }^{28}$ Relative quantification and statistics were estimated as the mean of three replicate assays calculated by the 7500 FAST sequence detection software version 2.3 (Applied Biosystems).

\section{Statistical Analysis}

Results are presented as means \pm SEM. Statistical significance for two-group comparisons in quantitative RT-PCR analysis was determined using unpaired $t$-tests using GraphPad QuickCalcs (GraphPad Software, Inc., La Jolla, CA; http:// www.graphpad.com/quickcalcs/ttest2). Comparisons of the numbers of immunohistochemical-positive vessels and IFpositive fibrocytes between two groups (bFGF versus control or VEGF versus control) were statistically analyzed using one-way analysis of variance, followed by Bonferroni's post hoc test. Differences with $P<0.05$ were considered statistically significant.

\section{Results}

\section{bFGF Treatment Promotes Angiogenesis and Inhibits Collagen mRNA Expression}

We first assessed the number of vWF-positive $\left(\mathrm{vWF}^{+}\right)$ vessels, including capillaries, arterioles, arteries, and lymph vessels, in bFGF-treated or control wounds on days 2, 4, 6, 7, and 14 after operation. The average number of $\mathrm{vWF}^{+}$vessels per field was significantly greater in the bFGF-treated wounds than in the control wounds on day $6(P<0.05)$ (Figure 2A). In addition, the average number of $\mathrm{vWF}^{+}$ vessels per field was significantly greater in the VEGF$\mathrm{A}-$ treated wounds than in the control wounds observed on days 2 and $4(P<0.05)$ (Figure $2 B)$. We further confirmed the positive effects of bFGF on angiogenesis by assessing the mRNA expression levels of the two endothelial cell markers, CD34 and CD31, using quantitative RT-PCR (real-time PCR). Compared to the control, bFGF-treated wounds showed a significant increase in CD34 mRNA expression on days 4,6 , and $14(P<0.0001)$ (Figure $2 \mathrm{C})$. CD31 mRNA expression was also significantly higher in bFGF-treated wounds than in control wounds on days 4 and 14 ( $P=0.0011$ and $P=0.0001$, respectively) (Figure 2D). These combined data further confirmed a positive effect of bFGF on angiogenesis. Regarding collagen expression in wounds, bFGF treatment for 6 days significantly decreased expression of collagen type I, III, and IV mRNA compared to control wounds $(P<0.0001)$ (Figure $2, \mathrm{E}-\mathrm{G})$. bFGF treatment for 14 days also significantly decreased expression of collagen type I, III, and IV mRNA expression compared to control wounds $(P<0.0001, P=0.0002$, and $P<0.0001$, respectively) (Figure 2, E-G). No significant difference in the three types of collagen mRNA expression was evident between bFGF-treated and control wounds on day 4 (Figure 2, E-G). On the other hand, bFGF mRNA expression in bFGF-treated wounds was significantly higher than that in control wounds on all three days $(P<0.0001)$ (Figure $2 \mathrm{H}$ ). This suggests that the persistent induction of 

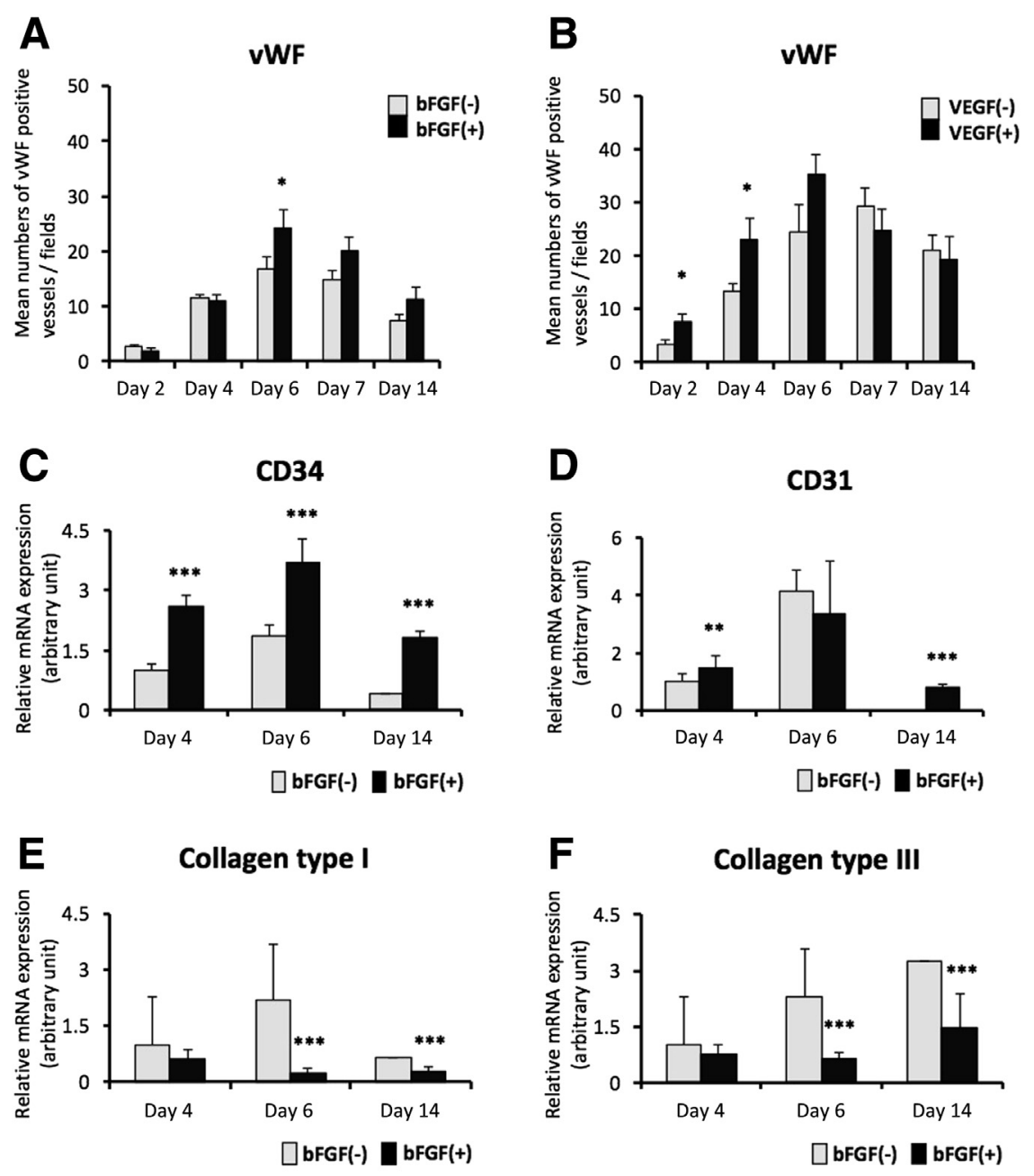

Figure 2 Positive effects of basic fibroblast growth factor (bFGF) on vascular formation in wounds. A and B: Wounds were treated with $(+)$ or without (-) bFGF (A) or vascular endothelial growth factor (VEGF; B). Ten to twelve randomly selected fields in wounds per tissue section were then examined, and the number of von Willebrand factor $(\mathrm{vWF})^{+}$vessels per field were counted on days $2,4,6,7$, and 14 after wounding and averaged. C-G: Enhanced expression of CD34, CD31, collagen type I, III, and IV, and bFGF mRNA in bFGF-treated $[\mathrm{bFGF}(+)]$ wounds. Real-time PCR analysis of CD34 (C), CD31 (D), collagen type I (E), III (F), and IV (G), and bFGF (H) mRNA expression in wounds on days 4,6 , and 14 after wounding. All values are presented as the means $\pm \operatorname{SEM}(\mathbf{A}-\mathbf{H})$. ${ }^{*} P<0.05$ versus bFGF( $(-)$ or versus $\operatorname{VEGF}(-)$; ${ }^{* *} P<0.01,{ }^{* * *} P<0.001$ versus non-bFGFtreated $[\operatorname{bFGF}(-)]$, as determined by $t$-test.
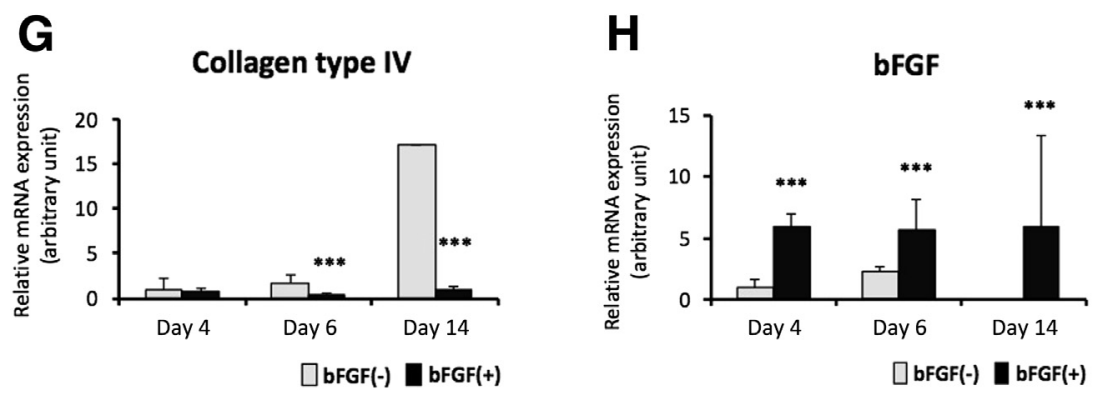

bFGF mRNA after bFGF treatment contributes to enhanced angiogenesis and inhibited collagen mRNA expression in bFGF-treated wounds.

\section{Specific Changes in Vascular Components in bFGF-Treated Wounds}

We next assessed the vessel densities in four different types of vessels in bFGF- or VEGF-A - treated wounds on days $2,4,6,7$, and 14 after operation. We considered immunohistochemically stained $\mathrm{CD} 34^{+} / \alpha-\mathrm{SMA}^{-}$vessels as capillaries, $\mathrm{CD}^{+} 4^{+} / \alpha-\mathrm{SMA}^{+}$vessels in the thin smooth muscle layer as arterioles, $\mathrm{CD} 34^{+} / \alpha-\mathrm{SMA}^{+}$vessels in the thick smooth muscle layer as arteries, and podoplanin $^{+}$vessels as lymph vessels (Figure 3A). Data from bFGF-treated wounds demonstrated significantly greater values of capillary density on day 6 and of arteriole density on days 4 and 6 compared with control wounds $(P<0.05)$. VEGF-A-treated wounds showed significantly higher values of capillary density on day 4 and of lymph vessel density on days 4 and 6, whereas VEGF-A treatment did not affect the values of arteriole density compared to control at all time points. The values of podoplanin ${ }^{+}$lymph vessel density were significantly 


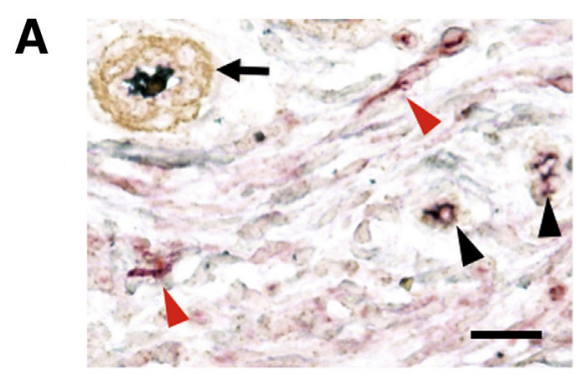

B

Capillary

FGF

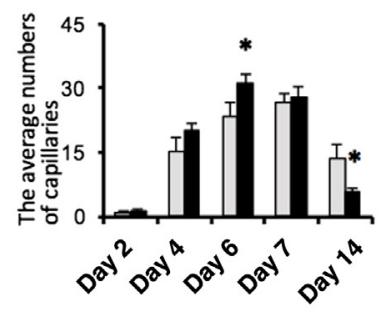

Arteriole

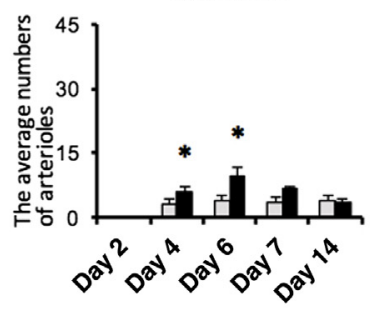

Artery

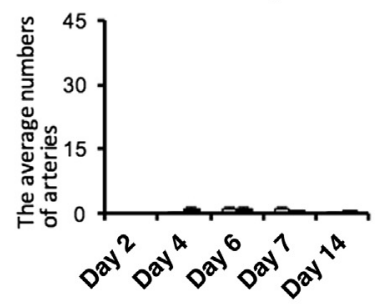

Arteriole

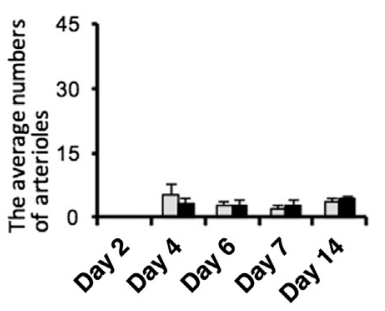

Artery

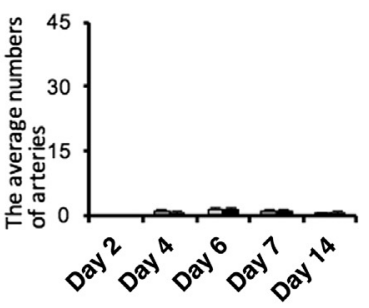

FGF(-)

$\mathrm{FGF}(+)$

Lymph vessel

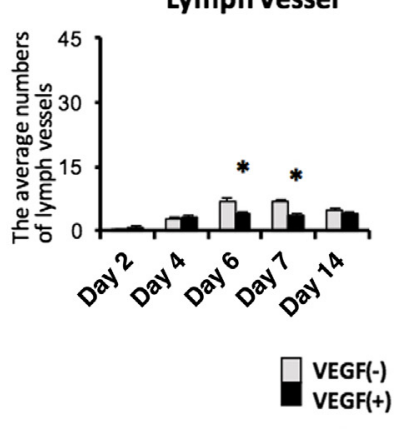

Lymph vessel

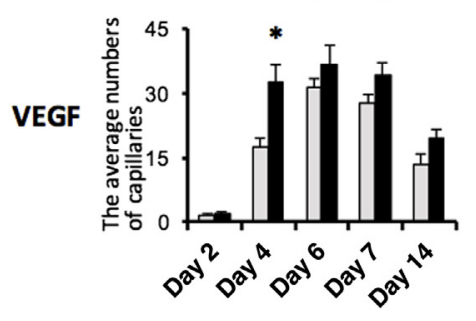

C

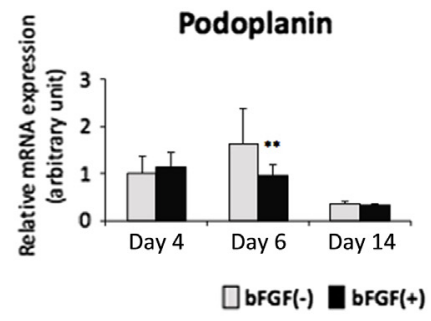

Figure 3 Specific changes in vascular components in basic fibroblast growth factor (bFGF)-treated wounds during healing. A: Triple immunohistochemistry for CD34 (red), podoplanin (black), and $\alpha$-smooth muscle actin ( $\alpha$-SMA; brown) in wound granulation tissues on day 6 after operation. Red arrowheads, black arrowheads, and the black arrow highlight $\mathrm{CD}_{3} 4^{+}$vessels, podoplanin ${ }^{+}$lymph vessels, and an $\alpha-\mathrm{SMA}^{+}$vessel, respectively. B: Changes in the values of vessel densities in capillaries, arterioles, arteries, and lymph vessels in bFGF- and vascular endothelial growth factor (VEGF)-A-treated wounds on days 2, 4, 6, 7, and 14 after operation. Ten randomly selected fields in wounds per tissue section were examined, and the number of these four histologic types of vessels per field was counted in each type of vessel in the bFGF- or VEGF-treated wounds and their respective controls. The average value of vessel density was calculated in each type of vessel. C: Inhibition of podoplanin mRNA expression in bFGF-treated wounds $[\mathrm{bFGF}(+)]$ on day 6 . Real-time PCR analysis of the mRNA expression of podoplanin was performed on days 4,6 , and 14 after treatment. All values are presented as the means \pm SEM (B and $\mathbf{C}$ ). ${ }^{*} P<0.05$ versus non-treated control, arbitrary units; ${ }^{*} P<0.01$ versus non-bFGF treated [bFGF(-)], as determined by $t$-test. Scale bar $=10 \mu \mathrm{m}(\mathbf{A})$. lower in bFGF-treated wounds than in control wounds on days 6 and $7(P<0.05)$, whereas they were significantly greater in VEGF-A-treated wounds than in control wounds on days 4 and $6(P<0.05)$ (Figure 3B). We then conducted real-time PCR analysis of podoplanin mRNA expression in bFGF-treated wounds and found that bFGF-treated wounds showed significantly lower levels of podoplanin mRNA when compared with control wounds on day $6(P=0.0011)$ (Figure 3C). The combined data suggested that bFGF treatment specifically up-regulated arterioles in treated wounds on day 6.

\section{bFGF Treatment Induces Capillary-Like Structures Composed of Fibrocytes}

Double IF staining focusing on the detection of fibrocytes demonstrated that $\mathrm{CD} 34^{+} /$procollagen $\mathrm{I}^{+}$fibrocyte was almost absent from the wounds on day 2, irrespective of bFGF treatment. However, on day 4, bFGF-treated wounds displayed a loose cellular network that was mainly composed of $\mathrm{CD}_{4} 4^{+} /$procollagen $\mathrm{I}^{+}$fibrocytes (Figure 4, $\mathrm{A}-\mathrm{C})$. This network was almost absent from non-bFGFtreated wounds (Figure 4D). On day 6, the $\mathrm{CD} 34^{+} /$procollagen $\mathrm{I}^{+}$fibrocytes in the bFGF-treated wounds 


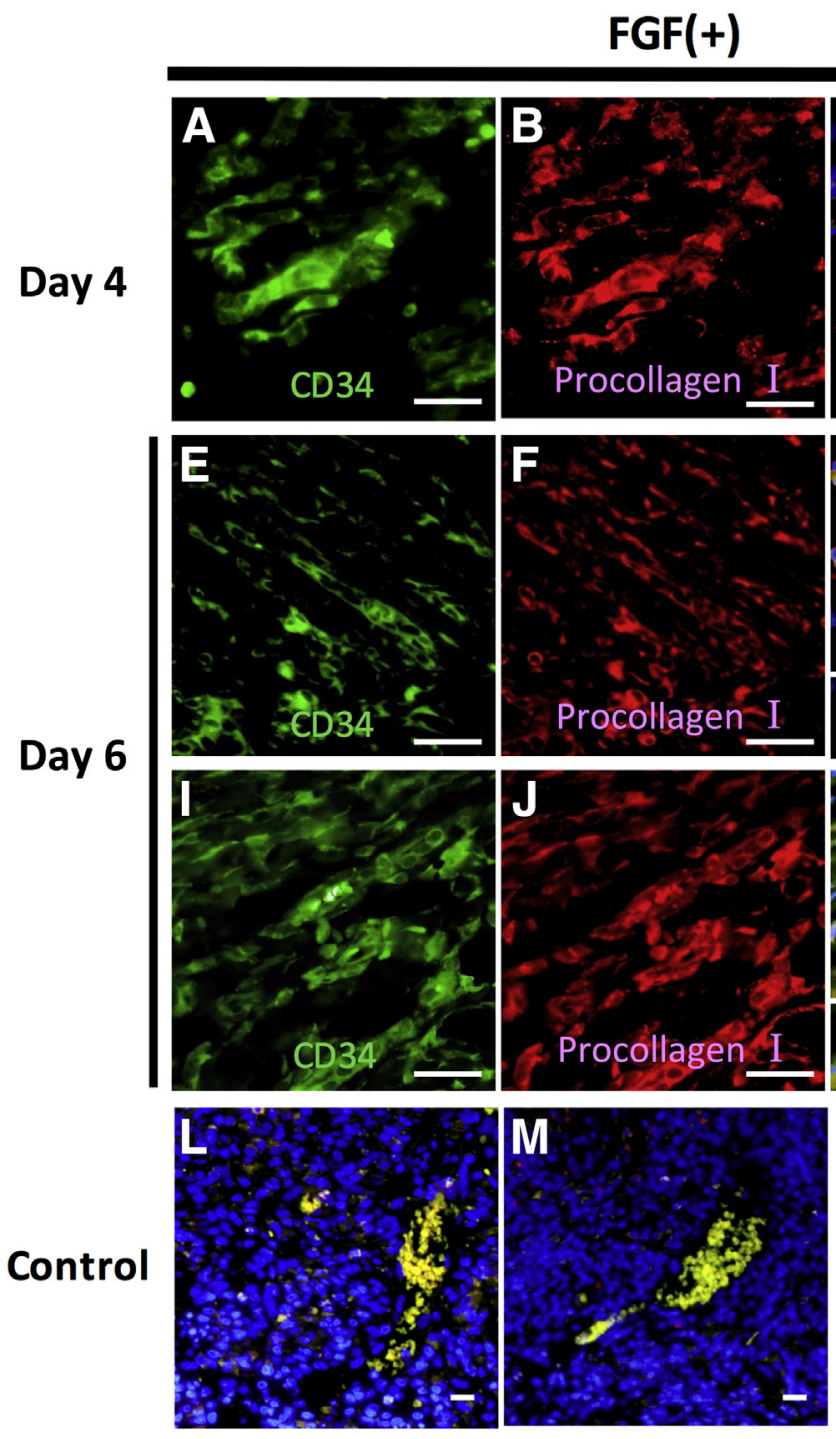

\section{N CD34/procollagen I}
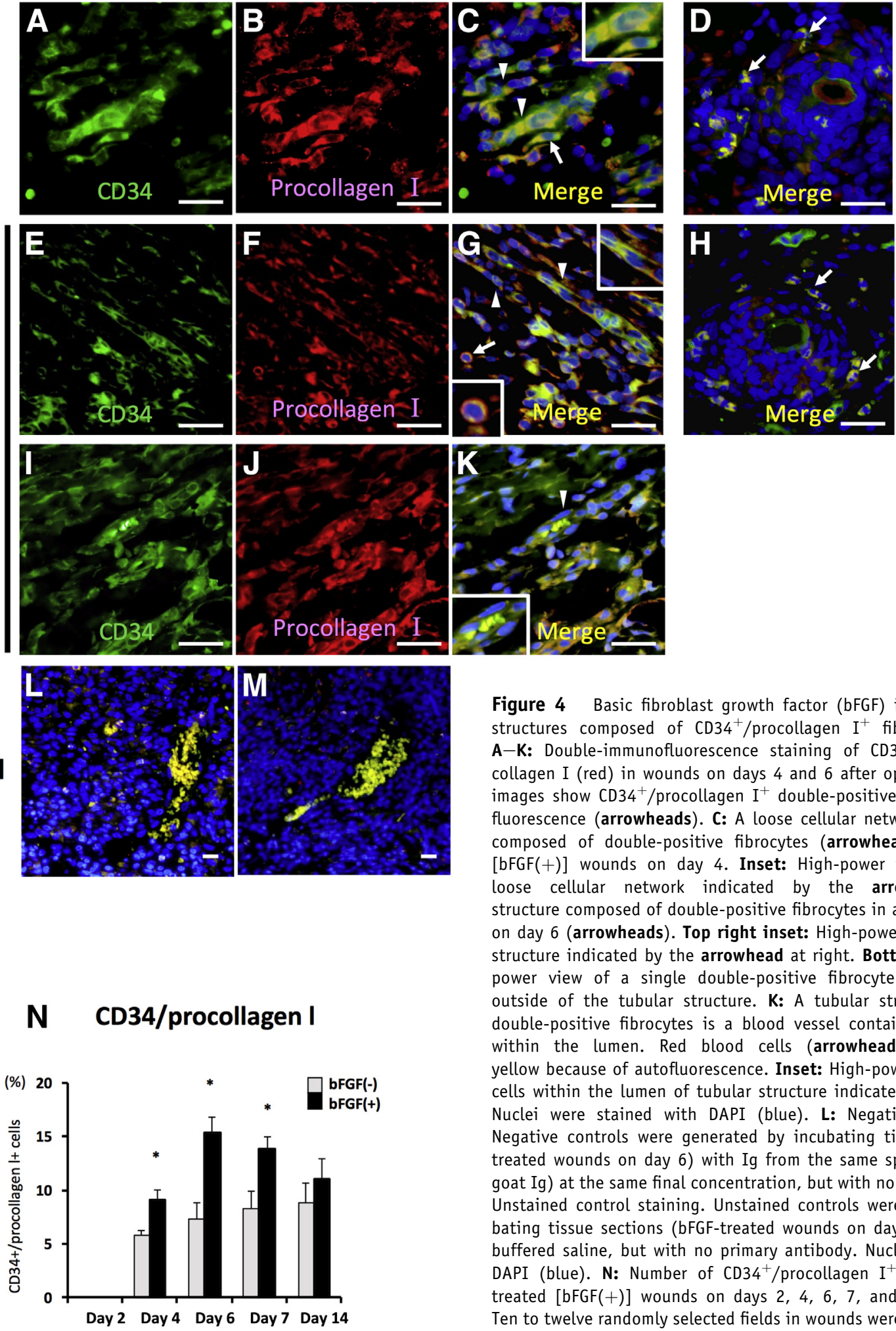

Figure 4 Basic fibroblast growth factor (bFGF) induces capillary-like structures composed of $\mathrm{CD}^{+} 4^{+} /$procollagen $\mathrm{I}^{+}$fibrocytes in wounds. A-K: Double-immunofluorescence staining of CD34 (green) and procollagen I (red) in wounds on days 4 and 6 after operation. The merged images show $\mathrm{CD}_{3} 4^{+}$/procollagen $\mathrm{I}^{+}$double-positive fibrocytes as yellow fluorescence (arrowheads). C: A loose cellular network structure mainly composed of double-positive fibrocytes (arrowheads) in bFGF-treated $[\mathrm{bFGF}(+)]$ wounds on day 4. Inset: High-power view of part of the loose cellular network indicated by the arrow. G: A tubular structure composed of double-positive fibrocytes in a bFGF-treated wound on day 6 (arrowheads). Top right inset: High-power view of the tubular structure indicated by the arrowhead at right. Bottom left inset: Highpower view of a single double-positive fibrocyte (arrow) infiltrating outside of the tubular structure. K: A tubular structure composed of double-positive fibrocytes is a blood vessel containing red blood cells within the lumen. Red blood cells (arrowhead) are identified as yellow because of autofluorescence. Inset: High-power view of red blood cells within the lumen of tubular structure indicated by the arrowhead. Nuclei were stained with DAPI (blue). L: Negative control staining. Negative controls were generated by incubating tissue sections (bFGFtreated wounds on day 6) with Ig from the same species (rabbit Ig and goat Ig) at the same final concentration, but with no primary antibody. M: Unstained control staining. Unstained controls were generated by incubating tissue sections (bFGF-treated wounds on day 6) with phosphatebuffered saline, but with no primary antibody. Nuclei were stained with

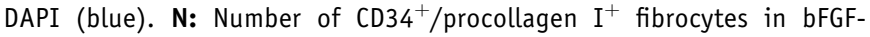
treated $[\mathrm{bFGF}(+)]$ wounds on days $2,4,6,7$, and 14 after treatment. Ten to twelve randomly selected fields in wounds were examined per tissue section, and the number of $\mathrm{CD}_{3} 4^{+} /$procollagen $\mathrm{I}^{+}$fibrocytes in granulation tissues was counted. The percentage of $\mathrm{CD}_{3} 4^{+}$/procollagen $\mathrm{I}^{+}$ fibrocytes was calculated as the mean number of double-positive cells relative to the total number of DAPI-positive granulation tissue cells. All values are presented as the means \pm SEM $(\mathbf{N}) .{ }^{*} P<0.05$ versus non-bFGF-treated wounds $[\mathrm{bFGF}(-)]$. Scale bars $=10 \mu \mathrm{m}(\mathbf{A}-\mathbf{M})$. 
A

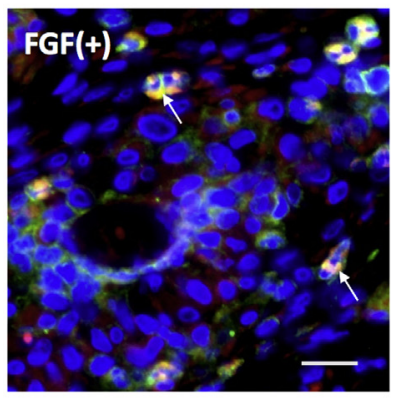

CD45/Procollagen I

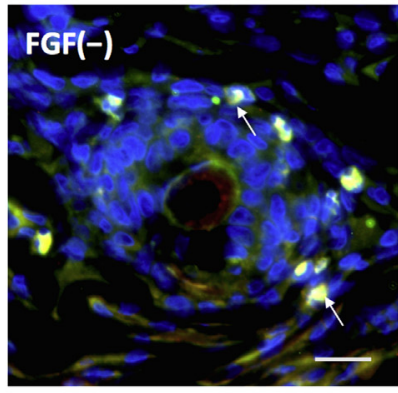

C

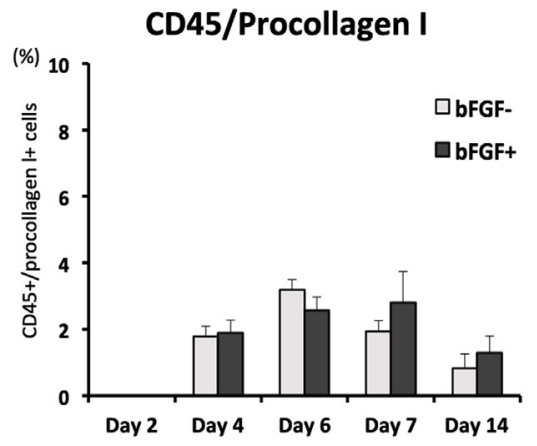

B

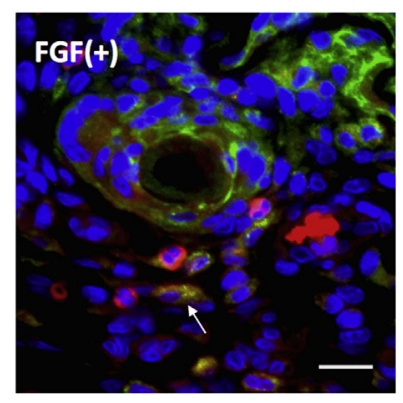

CD11b/Procollagen I

D

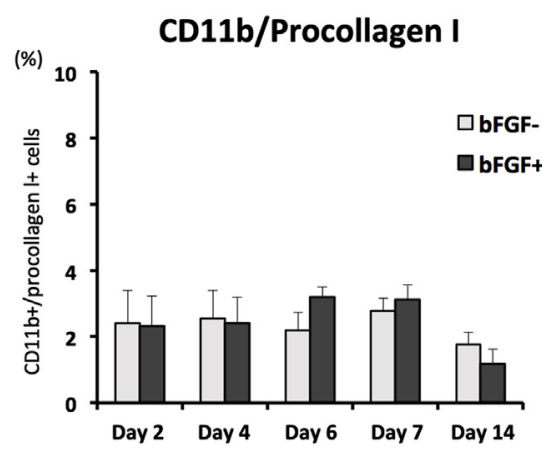

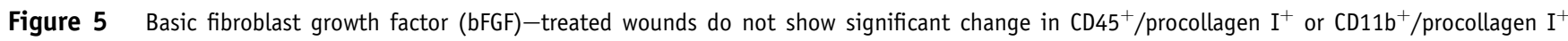
fibrocytes. A and B: Double-immunofluorescence staining of CD45 (green) and procollagen I (red; A) or CD11b (green) and procollagen I (red; B) in wounds on day 6 after bFGF treatment. Merged images show CD45/procollagen I (A) or CD11b/procollagen I (B) double-positive fibrocytes as yellow fluorescence (ar-

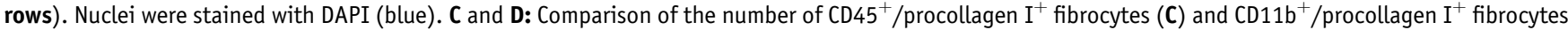
(D) between bFGF-treated $[\mathrm{bFGF}(+)]$ and non-treated $[\mathrm{bFGF}(-)]$ control wounds. Ten to twelve randomly selected fields in wounds were examined per tissue section. The percentage of double-positive fibrocytes in the granulation tissues was calculated as the mean number of positive cells relative to the total number of DAPI-positive granulation tissue cells. All values are presented as the means \pm SEM (C and $\mathbf{D})$. Scale bars $=10 \mu \mathrm{m}(\mathbf{A}$ and $\mathbf{B})$.

appeared to form thin-walled, capillary-like structures containing erythrocytes within the lumen (Figure 4, E-G, I-M), whereas non-bFGF-treated wounds lacked these capillary-like structures (Figure $4 \mathrm{H}$ ). By day 14, the capillary-like structures formed by $\mathrm{CD}_{3} 4^{+}$/procollagen $\mathrm{I}^{+}$ fibrocytes were almost absent from the wounds, irrespective of bFGF treatment, and were accompanied by a general reduction in vascularity. As shown in Figure 4N, the number of $\mathrm{CD}_{3} 4^{+} /$procollagen $\mathrm{I}^{+}$fibrocytes in bFGFtreated wounds increased rapidly after wound generation, peaked by day 6 , and then declined toward day 14 . The average numbers of CD $34^{+} /$procollagen $\mathrm{I}^{+}$fibrocytes were significantly increased compared with the control wounds on days 4,6 , and $7(P<0.05)$, whereas no difference was evident between bFGF-treated and non-bFGF-treated wounds on day 14 (Figure 4N). To confirm the specific induction of $\mathrm{CD}_{3} 4^{+} /$procollagen $\mathrm{I}^{+}$fibrocytes by bFGF treatment, we monitored the effect of bFGF on the accumulation of two other types of fibrocytes that were positive for CD45/procollagen I or CD11b/procollagen I (Figure 5, $\mathrm{A}$ and B). Although $\mathrm{CD}_{4} 5^{+} /$procollagen $\mathrm{I}^{+}$and $\mathrm{CD}_{11 \mathrm{~b}}{ }^{+}$ procollagen $\mathrm{I}^{+}$fibrocytes also increased in number after wound generation, no differences in the numbers of these two types of fibrocytes were found between bFGF-treated and non-bFGF-treated wounds (Figure 5, C and D). Furthermore, bFGF-treated wounds lacked capillary-like structures composed of either type of fibrocyte (ie, double positive for CD45/procollagen I or CD11b/procollagen I), at all time points (Figure 5, A and B). The combined data indicated that bFGF treatment specifically induces capillary-like structures composed of $\mathrm{CD} 34^{+} /$procollagen $\mathrm{I}^{+}$fibrocytes in wounds.

The bFGF/FGFR1 System Is Required for the Accumulation of $\mathrm{CD}_{34}{ }^{+} /$Procollagen $\mathrm{I}^{+}$Fibrocytes in Wounds

To confirm the specific accumulation of $\mathrm{CD} 34^{+} /$procollagen $\mathrm{I}^{+}$fibrocytes in bFGF-treated wounds, we next immunohistochemically analyzed the effect of VEGF-A treatment on the formation of these fibrocytes in wounds. In VEGF-A-treated wounds, CD34 ${ }^{+} /$procollagen $\mathrm{I}^{+}$fibrocytes on day 7 were mainly clustered around tubular structures in the wounds, which were clearly distinct from the capillary-like structures composed of $\mathrm{CD}_{34}{ }^{+}$/procollagen $\mathrm{I}^{+}$fibrocytes in the bFGF-treated wounds (Figure 6A). No difference in the number of $\mathrm{CD}^{+} 4^{+}$/procollagen $\mathrm{I}^{+}$fibrocytes compared to control was found in the VEGF-A-treated wounds over the entire course, except on day 4 (Figure 6B). In addition, we conducted double IF staining for CD34 and the typical endothelial progenitor cell marker Flk-1, and compared 
A
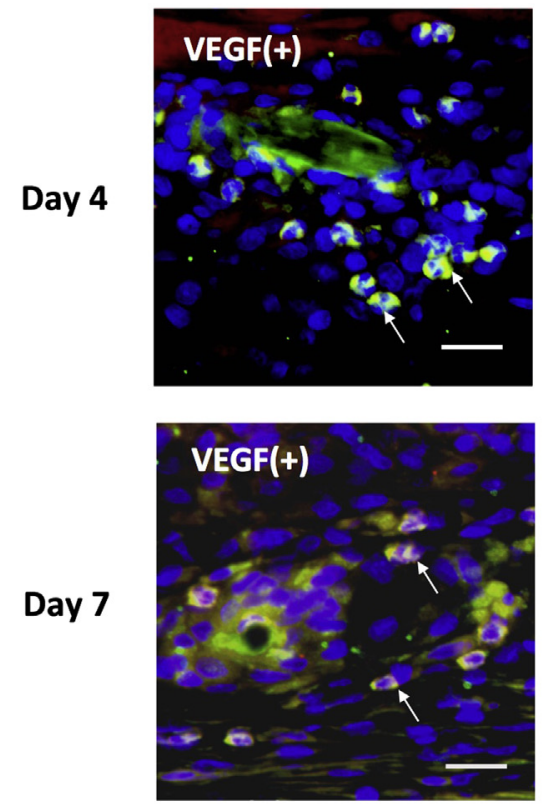

B
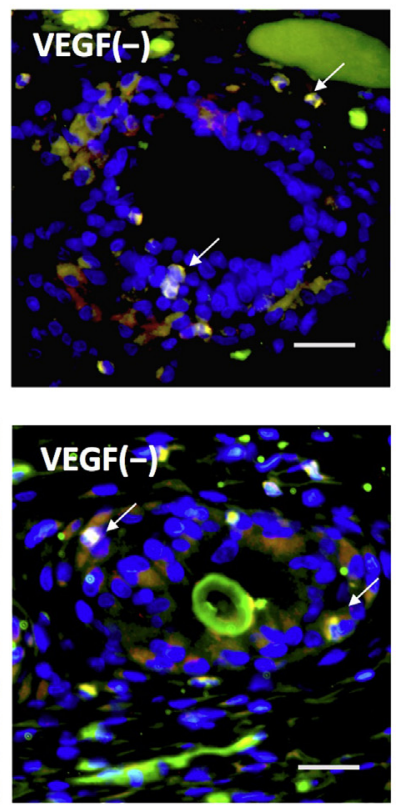

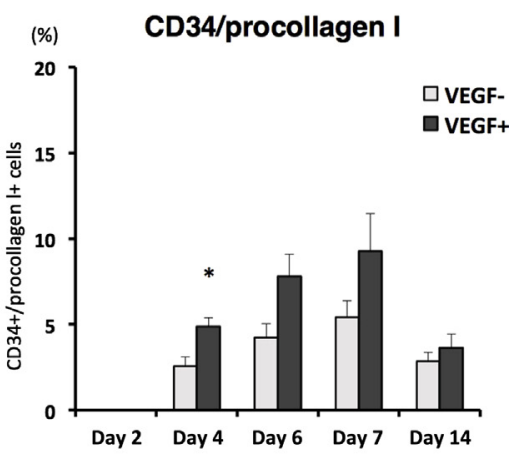

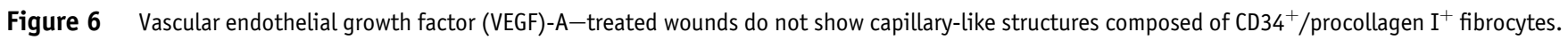
A: Double-immunofluorescence staining of CD34 (green) and procollagen I (red) in wounds on days 4 and 7 after VEGF-A treatment. Merged images showing

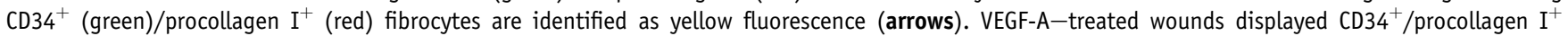
fibrocytes mainly clustered around thin-walled tubular structures. Nuclei were stained with DAPI (blue). B: The number of CD34 $4^{+} / \mathrm{procollagen} \mathrm{I}^{+}$fibrocytes in VEGF-A-treated $[\operatorname{VEGF}(+)]$ and non-treated $[\operatorname{VEGF}(-)]$ wounds on days 2, 4, 6, 7, and 14 after treatment. Ten to twelve randomly selected fields in wounds were examined per tissue section. The percentage of double-positive fibrocytes in granulation tissues was calculated as the mean number of positive cells relative to the total number of DAPI-positive granulation tissue cells. All values are presented as the means $\pm \mathrm{SEM}(\mathbf{B}) .{ }^{*} P<0.05$ versus non-VEGF-A-treated wounds. Scale bars $=10 \mu \mathrm{m}(\mathbf{A})$.

the expression patterns of $\mathrm{CD} 34^{+} / \mathrm{Flk}-1^{+}$cells between VEGF-A- and bFGF-treated wounds. In this analysis, $\mathrm{CD} 34^{+} / \mathrm{Flk}-1^{+}$cells on day 4 mainly clustered within tubular structures in VEGF-A-treated wounds (Figure 7A), whereas similar structures were almost absent in bFGF-treated wounds as well as in the respective controls for the wounds treated with either cytokine (Figure $7, \mathrm{~B}-\mathrm{D}$ ). The number of $\mathrm{CD} 34^{+} / \mathrm{Flk}-1^{+}$cells in VEGF-A-treated wounds was markedly increased on days 2 and 4 and was significantly higher than that in the control wounds $(P<0.05)$ (Figure $7 \mathrm{E})$. However, in bFGF-treated wounds, the number of double-positive cells on day 4 was lower than that in VEGF-A-treated wounds and was not significantly different from that in control wounds over the entire course (Figure 7F).

To further assess the specificity of bFGF-induced capillary-like structures, we knocked down FGFR1 by FGFR1 siRNA injection. Before knockdown by FGFR1 siRNA, double IF staining for FGFR1 expression in CD34-positive cells demonstrated FGFR1 expression in the CD34-positive cells that partially formed capillary structures in bFGF-treated wounds (Figure 8A), indicating that $\mathrm{CD}_{3} 4^{+}$/procollagen $\mathrm{I}^{+}$fibrocytes could express FGFR1. We next injected FGFR1 siRNA, followed by bFGF treatment, on days $2,4,6,7$, and 14 . The FGFR 1 siRNA (siFGFR1)-treated group showed significantly decreased FGFR1 mRNA expression on days 4, 6, and 7 after bFGF treatment $(P=0.0002, P<0.0001$, and $P=0.0001$, respectively) (Figure $8 \mathrm{~B}$ ), confirming the effectiveness of FGFR1 knockdown by FGFR1 siRNA injection. Double IF staining for estimation of the effect of FGFR1 knockdown on capillary-like structure formation showed that there were fewer capillary-like structures with $\mathrm{CD} 34^{+} /$procollagen $\mathrm{I}^{+}$fibrocytes in the siFGFR 1 group than in the respective siRNA control (siCON)treated group (Figure 8C). Accordingly, the number of $\mathrm{CD} 34^{+}$/procollagen $\mathrm{I}^{+}$fibrocytes in the siFGFR1 group was significantly decreased compared with that in the respective siCON group on days 4,6 , and $7(P<0.05)$ (Figure 8D). The decline in the number of capillary-like structures in the siFGFR1 group was confirmed using real-time PCR analysis of CD34 and CD31 mRNA expression on day 6 , which showed that the siFGFR1 group exhibited significantly decreased expression of CD34 and CD31 mRNA compared with the respective siCON control (CD34, $P<0.0001 ;$ CD31, $P<0.0001$ ) (Figure $8 \mathrm{E}$ ). The siFGFR1 group on day 6 also showed significantly decreased expression of collagen III and IV mRNA $(P<0.0001)$, whereas the same group exhibited increased expression of collagen type I mRNA compared to the siCON control (Figure $8 \mathrm{~F}$ ). The expression of CD34, CD31, and collagen type I mRNA in the siFGFR1 


\section{CD34/Flk-1}

A

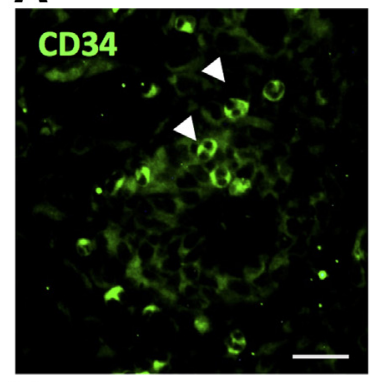

B

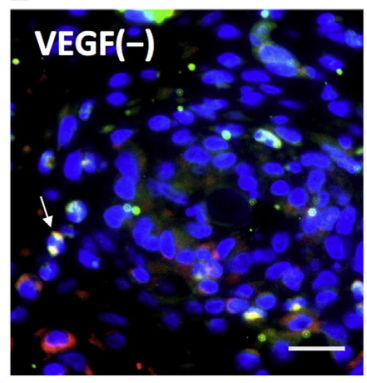

E

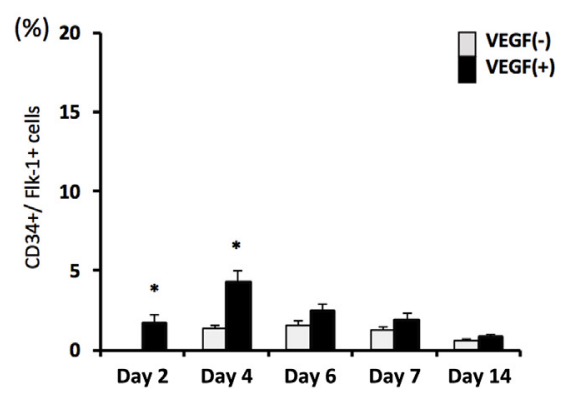

C
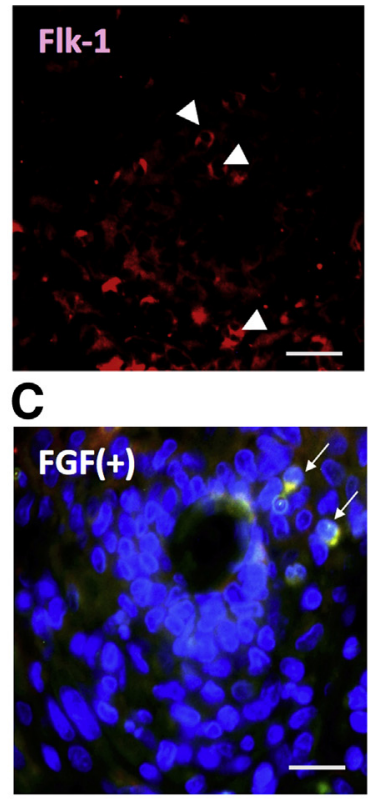

$\mathbf{F}$

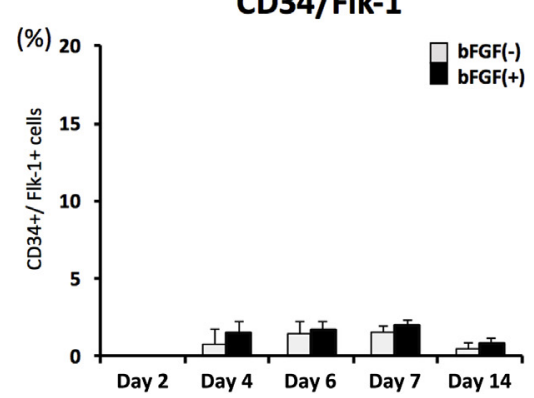

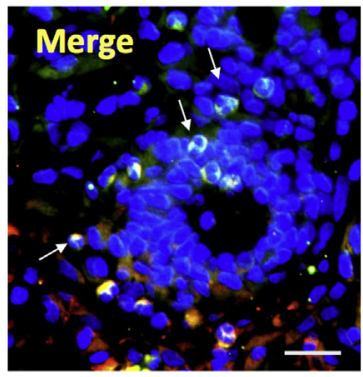

D

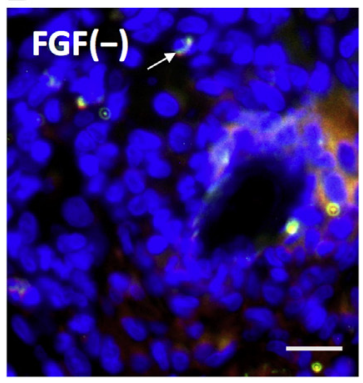

CD34/Flk-1

PFGF(-) $\mathrm{GF}(+)$

Figure 7 Different expression patterns of $\mathrm{CD} 4^{+} /$fatal liver kinase-1 (Flk-1) ${ }^{+}$cells between vascular endothelial growth factor (VEGF)-A- and basic fibroblast growth factor (bFGF)-treated wounds. A-D: Double-immunofluorescence staining of CD34 (green) and Flk-1 (red) in wounds after VEGF-A and bFGF treatment. Arrowheads indicate single-positive (CD34 or Flk-1) cells. $\mathrm{CD}_{4} 4^{+} / \mathrm{Flk}-1^{+}$ cells in VEGF-A-treated (A) and non-VEGF-Atreated $[\operatorname{VEGF}(-)]$ control (B) wounds, and in bFGF-treated $[\mathrm{FGF}(+)](\mathbf{C})$ and non-FGF $[\mathrm{FGF}(-)]$ control (D) wounds, on day 4. The merged images show CD34 (green)/Flk-1 (red) double-positive cells as yellow fluorescence (arrows). Nuclei were stained with DAPI (blue). In A, the double-positive cells are mainly located in a tubular structure close to the lumen. E: Comparison of the number of CD34 ${ }^{+} /$Flk- $1^{+}$cells in VEGF-A-treated [VEGF $\left.(+)\right]$ and untreated $[\operatorname{VEGF}(-)]$ wounds on days $2,4,6$, 7, and 14 after treatment. F: Comparison of the number of $\mathrm{CD}_{3} 4^{+} / \mathrm{Flk}^{-} 1^{+}$cells in bFGF-treated $[\mathrm{bFGF}(+)]$ and untreated $[\mathrm{bFGF}(-)]$ control wounds over the course of healing. In $\mathbf{E}$ and $\mathbf{F}, 10$ to 12 randomly selected fields in wounds were examined per tissue section. The percentage of double-positive cells in granulation tissues was calculated as the mean number of positive cells relative to the total number of DAPI-positive granulation tissue cells. All values are presented as the means \pm SEM (E and $\mathbf{F}$ ). ${ }^{*} P<0.05$ versus non-VEGF-A-treated wound. Scale bars = $10 \mu \mathrm{m}$ (A-D).

group (Figure 8, E and F) was the opposite pattern to the bFGF-treated wounds without knocking down of FGFR1 on day 6 (Figure 2, C-E). These combined data indicated that the bFGF/FGFR1 system is required for induction of capillary-like structures composed of CD $34^{+} /$procollagen $\mathrm{I}^{+}$fibrocytes in the wounds and that the expression levels of CD34, CD31, and collagen type I mRNA in bFGFtreated wounds are mediated, at least in part, through FGFR1.

\section{Discussion}

In this study, we identified capillary-like structures formed by $\mathrm{CD} 4^{+} /$procollagen $\mathrm{I}^{+}$fibrocytes in bFGF-treated wounds. This finding suggests a potential mechanism of bFGFinduced angiogenesis that is mainly because of enhanced formation of vessels with $\mathrm{CD} 34^{+} /$procollagen $\mathrm{I}^{+}$fibrocytes. We found that bFGF treatment of wounds demonstrated the following: i) significantly enhanced formation of arterioles on days 4 and 6; ii) markedly enhanced formation of capillarylike structures composed of $\mathrm{CD}_{3} 4^{+} /$procollagen $\mathrm{I}^{+}$fibrocytes that were lacking in VEGF-A-treated wounds; iii) a lack of accumulation of $\mathrm{CD}_{4} 5^{+} /$procollagen $\mathrm{I}^{+}$or $\mathrm{CD} 11 \mathrm{~b}^{+} /$ procollagen $\mathrm{I}^{+}$fibrocytes; iv) enhanced expression of CD34, CD31, and bFGF mRNA and reduced expression of podoplanin and collagen type I, III, and IV mRNA; and v) FGFR1 siRNA injection, followed by bFGF treatment, markedly inhibited formation of capillary-like structures with $\mathrm{CD} 34^{+} /$ procollagen $\mathrm{I}^{+}$fibrocytes. FGFR1 siRNA treatment also inhibited CD34 and CD31 mRNA expression and promoted collagen type I mRNA expression, which was the opposite pattern to the bFGF-treated wounds without knocking down of FGFR1. These combined data highlight the angiogenetic properties of $\mathrm{CD}_{3} 4^{+} /$procollagen $\mathrm{I}^{+}$fibrocytes that were specifically induced by bFGF in wounds, and provide new insight into the active contribution of fibrocytes for vascular formation in wounds.

Previous investigation of bFGF-treated collagen gels demonstrated that co-culture of endothelial cells and 
A
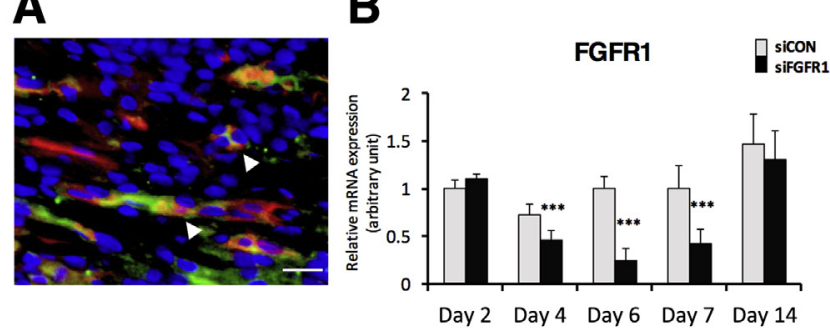

C
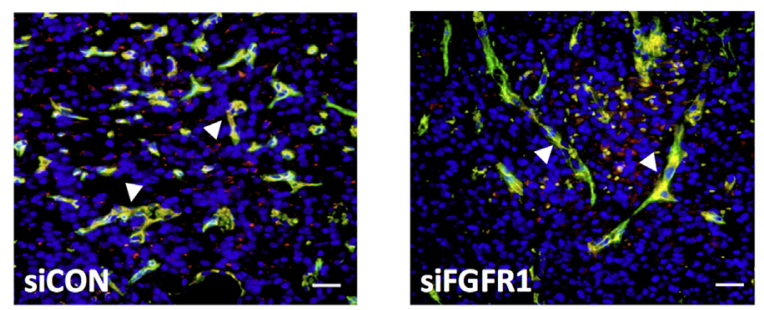

D

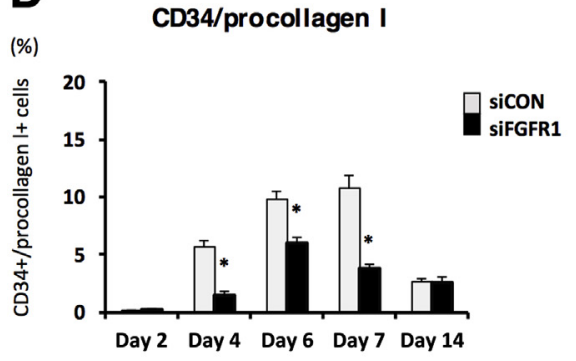

E CD34
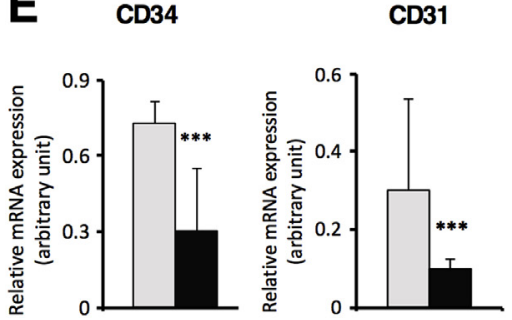

F Collagen type I

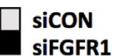

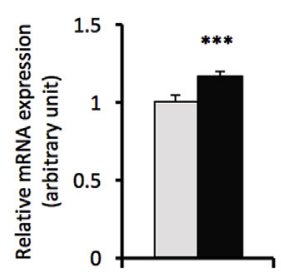

Figure 8 The basic fibroblast growth factor (bFGF)/fibroblast growth factor receptor 1 (FGFR1) system is required for capillary-like structures composed of $\mathrm{CD} 4^{+} /$procollagen $\mathrm{I}^{+}$fibrocytes in wounds. A: Doubleimmunofluorescence staining of CD34 (green) and FGFR1 (red) in wounds on day 6 after bFGF treatment. The merged image shows CD34 (green)/FGFR1 (red) double-positive cells as yellow fluorescence (arrowheads). Nuclei were stained with DAPI (blue). The merged images show FGFR1 expression in the CD34-positive cells that partially formed capillary structures. B: Reduction of FGFR1 mRNA expression by FGFR1 siRNA injection. FGFR1 mRNA expression in FGFR1 siRNA (siFGFR1)-treated groups on days 2, 4, 6, 7, and 14 after treatment was analyzed using real-time PCR. C: Double-immunofluorescence staining of CD34 (green) and procollagen I (red) in wounds on days 6 . Capillary structures composed of CD34 (green) and procollagen I (red) double-positive fibrocytes in siRNA control (siCON)-treated wounds (left panel) and siFGFR1-treated wounds (right panel). The merged images show $\mathrm{CD}_{4} 4^{+}$/procollagen $\mathrm{I}^{+}$fibrocytes as yellow fluorescence (arrowheads). Nuclei were stained with DAPI (blue). D: Reduction in the number of $\mathrm{CD}_{3} 4^{+}$/ procollagen $\mathrm{I}^{+}$fibrocytes in siFGFR1 groups on days 4,6 , and 7 . Ten to twelve randomly selected fields in the treated wounds on days 2, 4, 6, 7, and 14 after treatment were examined per tissue section, and the number of $\mathrm{CD}_{4} 4^{+} /$procollagen $\mathrm{I}^{+}$fibrocytes in granulation tissues was counted. The percentage of $\mathrm{CD}_{3} 4^{+} /$procollagen $\mathrm{I}^{+}$fibrocytes was calculated as the mean number of positively stained cells relative to the total number of DAPIpositive granulation tissue cells. $\mathbf{E}$ and $\mathbf{F}$ : Real-time PCR analysis of CD34, CD31 mRNA expression (E), and collagen type I, III, and IV mRNA expression (F) in siCON and siFGFR1 groups on day 6. Inhibition of CD34 and CD31 mRNA expression (E) and promotion of collagen I mRNA expression (F) in siFGFR1 groups. All values are presented as the means \pm SEM (B and $\mathbf{D}-\mathbf{F})$. ${ }^{*} P<0.05$ versus the siCON group; ${ }^{* *} P<0.001$ versus the siCON group, as determined using $t$-test. Scale bars $=10 \mu \mathrm{m}(\mathbf{A}$ and $\mathbf{C})$.

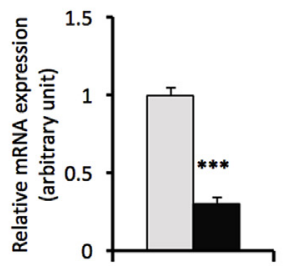

Collagen type IV

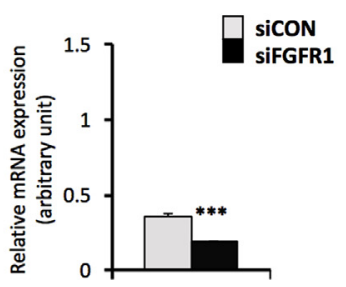

fibroblasts elicited an angiogenic response, suggesting that bFGF markedly influences the cross talk between endothelial cells and fibroblasts. ${ }^{29,30}$ Another study showed that FGF could induce an angiogenic phenotype in endothelial cells because of induction of matrix metalloproteinases 2 and 9, resulting in marked formation of capillary-like structures. ${ }^{31}$ When endothelial cells were cultured with type I collagen, bFGF promoted invasion of endothelial cells and formation of capillary-like structures. ${ }^{32}$ Therefore, as suggested in previous experiments, ${ }^{29,30}$ there might exist a cross talk between endothelial cells and fibroblasts. Based on the present findings of capillary-like structures formed by the fibrocytes, the presumed intimate relationship between endothelial cells and fibroblasts might represent the angiogenic phenotype of fibrocytes positive for CD34/procollagen I that are specifically induced by bFGFs. Interestingly, a recent investigation showed that another type of fibrocyte that expresses CD13/collagen I could inhibit angiogenesis

through enhanced production of an anti-angiogenic factor (thrombospondin 1). ${ }^{21}$ However, the present findings of marked formation of capillary-like structures with $\mathrm{CD} 34^{+} /$ procollagen $\mathrm{I}^{+}$fibrocytes indicated that $\mathrm{CD} 34^{+} /$procollagen $\mathrm{I}^{+}$fibrocytes have a proangiogenic role in wounds. Therefore, various types of fibrocytes might have different roles in wound healing, and the specific phenotypes of fibrocytes that are required for angiogenesis need to be clarified for elucidation of the mechanisms of angiogenesis in wounds. The two-dimensional measurements of vessel density in repaired tissues, which were performed in this study, represent a standard method to evaluate vascularization. However, recent investigation into the accuracy of two- and three-dimensional analysis of capillary networks in computer-generated models have shown that the threedimensional approach is more appropriate than the twodimensional approach because vessel density estimated by two-dimensional analysis does not truly reflect the density 
of vessels with complicated anatomy. ${ }^{33}$ Therefore, threedimensional analysis will be necessary in the future to reduce the estimation error of the levels of vascularization composed of $\mathrm{CD} 34^{+} /$procollagen $\mathrm{I}^{+}$fibrocytes in wounds.

Type I collagen has been shown to play an important role in capillary morphogenesis and maturation. ${ }^{34,35}$ Recently, type I collagen was shown to promote shape change in endothelial cells that closely imitated precapillary formation, because addition of collagen type I caused endothelial cells to partially retract and exhibit a spindle-shaped morphology, leading to formation of tubes with lumens. ${ }^{36,37}$ Previous investigation in transformation of corneal endothelial cells demonstrated that bFGF plays an important role for endothelial-mesenchymal transformation in corneal endothelial cells. ${ }^{38}$ In this process, bFGF also enhanced secretion of collagen type I from the cells, presumably leading to retrocorneal fibrous membrane. ${ }^{38-40}$ In the present study, bFGF treatment in wounds induced the angiogenic phenotype of fibrocytes that coexpress CD34/procollagen type I. We therefore speculate that, in the course of further differentiation of $\mathrm{CD}_{3} 4^{+} /$procollagen $\mathrm{I}^{+}$fibrocytes, this type of fibrocyte could increase the production and secretion of collagen type $\mathrm{I}^{1}{ }^{1}$ and finally transform into fibroblasts/myofibroblasts through endothelial-mesenchymal transformation specifically induced by bFGF. It has been indicated that the fibrocytes can differentiate into fibroblasts/myofibroblasts both in vitro and in vivo. Therefore, during the process of fibrocyte differentiation associated with the phenotypic changes, endothelial-mesenchymal transformation might be a part of the process where angiogenic phenotype of fibrocytes (eg, CD $34^{+} /$procollagen $\mathrm{I}^{+}$fibrocytes) can further differentiate into fibroblasts/myofibroblasts.

Previous investigation showed that treatment with a low dose of bFGF was effective in inducing arteriogenesis in an acute femoral artery occlusion model, ${ }^{41}$ with the bFGFtreated group showing a markedly decreased width of luminal dilation compared with the VEGF-treated group. Later investigation supported this finding, showing that anti-bFGF treatment, but not anti-VEGF treatment, inhibited the growth of arterioles in coronary angiogenesis. ${ }^{42}$ The findings of the present study showing that bFGF treatment induced a markedly greater proportion of arterioles on days 4 and 6 that was lacking in VEGF-A-treated wounds are consistent with these previous findings.

In contrast to the induction of $\mathrm{CD} 34^{+} /$procollagen $\mathrm{I}^{+}$ fibrocytes by bFGF treatment, bFGF treatment also induced a significant reduction of collagen type I mRNA, as confirmed by real-time PCR analysis in FGFR1 siRNA injected wounds. Previously, bFGF treatment in osteoblasts has shown to inhibit collagen type I gene expression through the activation of the extracellular signal-regulated kinase pathway. ${ }^{43}$ It is not clear whether bFGF treatment in dermal fibroblasts has an ability to inhibit collagen type I expression. Our previous investigation showing that bFGF treatment in cardiac fibroblasts inhibited collagen type I mRNA $^{28}$ suggests that bFGF treatment in dermal fibroblasts could also inhibit collagen type I expression, presumably leading to a significant reduction of collagen type I expression in the treated wounds. Further study will be needed to clarify the mechanisms underlying collagen type I expression in dermal fibroblasts treated by bFGF in wounds.

Among reported markers of lymphatic endothelial cells, such as CD31, VEGF receptor-3, Prox-1, desmoplakin, ${ }^{44}$ and podoplanin, podoplanin was first used to identify these cells. ${ }^{45}$ Later investigation demonstrated that podoplanin is expressed in small lymphatic vessels and lymphatic collecting vessels in normal human tissues, but not in large lymphatic vessels. ${ }^{46,47}$ In this study, bFGF treatment $(10 \mathrm{ng})$ inhibited the formation of podoplanin (D2-40)-positive lymphatic vessels, as confirmed by realtime PCR analysis. However, implantation of a high-dose bFGF pellet ( $80 \mathrm{ng}$ ) into the mouse cornea induced lymphangiogenesis, as detected by double staining with CD31 and VEGF receptor-3 antibodies. $^{44}$ In normal rat skin wounds, it is unclear which type of lymphatic vessel is detectable by podoplanin and whether the pattern of lymphangiogenesis differs between high- and low-dose bFGF treatments. However, based on the present findings, treatment with a low dose of bFGF (10 ng) can effectively inhibit the formation of certain types of lymphatic vessels, presumably formation of small lymphatic vessels in rat skin wound healing.

In conclusion, bFGF treatment specifically induces an angiogenic phenotype of $\mathrm{CD}_{3} 4^{+} /$procollagen $\mathrm{I}^{+}$fibrocytes in granulation tissues, which could be a main contributor to bFGF-induced angiogenesis in wounds.

\section{Acknowledgment}

We thank Kayo Tsuburaya (School of Medicine, Toho University, Tokyo, Japan) for technical assistance in morphological analysis.

\section{References}

1. Bucala R, Spiegel LA, Chesney J, Hogan M, Cerami A: Circulating fibrocytes define a new leukocyte subpopulation that mediates tissue repair. Mol Med 1994, 1:71-81

2. Abe R, Donnelly SC, Peng T, Bucala R, Metz CN: Peripheral blood fibrocytes: differentiation pathway and migration to wound sites. J Immunol 2001, 166:7556-7562

3. Grieb G, Bucala R: Fibrocytes in fibrotic diseases and wound healing. Adv Wound Care (New Rochelle) 2012, 1:36-40

4. Reilkoff RA, Bucala R, Herzog EL: Fibrocytes: emerging effector cells in chronic inflammation. Nat Rev Immunol 2011, 11: 427-435

5. Quan TE, Cowper S, Wu SP, Bockenstedt LK, Bucala R: Circulating fibrocytes: collagen-secreting cells of the peripheral blood. Int J Biochem Cell Biol 2004, 36:598-606

6. Mehrad B, Burdick MD, Zisman DA, Keane MP, Belperio JA, Strieter RM: Circulating peripheral blood fibrocytes in human fibrotic interstitial lung disease. Biochem Biophys Res Commun 2007, 353:104-108 
7. Sakai N, Wada T, Yokoyama H, Lipp M, Ueha S, Matsushima K, Kaneko S: Secondary lymphoid tissue chemokine (SLC/CCL21)/CCR7 signaling regulates fibrocytes in renal fibrosis. Proc Natl Acad Sci U S A 2006, 103:14098-14103

8. Phillips RJ, Burdick MD, Hong K, Lutz MA, Murray LA, Xue YY, Belperio JA, Keane MP, Strieter RM: Circulating fibrocytes traffic to the lungs in response to CXCL12 and mediate fibrosis. J Clin Invest 2004, 114:438-446

9. Keeley EC, Mehrad B, Strieter RM: The role of fibrocytes in fibrotic diseases of the lungs and heart. Fibrogenesis Tissue Repair 2011, 4:2

10. Yang L, Scott PG, Dodd C, Medina A, Jiao H, Shankowsky HA, Ghahary A, Tredget EE: Identification of fibrocytes in postburn hypertrophic scar. Wound Repair Regen 2005, 13:398-404

11. Wang JF, Jiao H, Stewart TL, Shankowsky HA, Scott PG, Tredget EE: Fibrocytes from burn patients regulate the activities of fibroblasts. Wound Repair Regen 2007, 15:113-121

12. Raffetto JD, Khalil RA: Matrix metalloproteinases and their inhibitors in vascular remodeling and vascular disease. Biochem Pharmacol 2008, 75:346-359

13. Moore BB, Murray L, Das A, Wilke CA, Herrygers AB, Toews GB: The role of CCL12 in the recruitment of fibrocytes and lung fibrosis. Am J Respir Cell Mol Biol 2006, 35:175-181

14. Hashimoto N, Jin H, Liu T, Chensue SW, Phan SH: Bone marrowderived progenitor cells in pulmonary fibrosis. J Clin Invest 2004, $113: 243-252$

15. Wang CH, Huang CD, Lin HC, Lee KY, Lin SM, Liu CY, Huang KH, Ko YS, Chung KF, Kuo HP: Increased circulating fibrocytes in asthma with chronic airflow obstruction. Am J Respir Crit Care Med 2008, 178:583-591

16. Schmidt M, Sun G, Stacey MA, Mori L, Mattoli S: Identification of circulating fibrocytes as precursors of bronchial myofibroblasts in asthma. J Immunol 2003, 171:380-389

17. Andersson-Sjoland A, de Alba CG, Nihlberg K, Becerril C, Ramirez R, Pardo A, Westergren-Thorsson G, Selman M: Fibrocytes are a potential source of lung fibroblasts in idiopathic pulmonary fibrosis. Int J Biochem Cell Biol 2008, 40:2129-2140

18. Mori L, Bellini A, Stacey MA, Schmidt M, Mattoli S: Fibrocytes contribute to the myofibroblast population in wounded skin and originate from the bone marrow. Exp Cell Res 2005, 304:81-90

19. Hartlapp I, Abe R, Saeed RW, Peng T, Voelter W, Bucala R, Metz CN: Fibrocytes induce an angiogenic phenotype in cultured endothelial cells and promote angiogenesis in vivo. FASEB J 2001, 15: 2215-2224

20. Kao HK, Chen B, Murphy GF, Li Q, Orgill DP, Guo L: Peripheral blood fibrocytes: enhancement of wound healing by cell proliferation, re-epithelialization, contraction, and angiogenesis. Ann Surg 2011, 254:1066-1074

21. Li J, Tan H, Wang X, Li Y, Samuelson L, Li X, Cui C, Gerber DA: Circulating fibrocytes stabilize blood vessels during angiogenesis in a paracrine manner. Am J Pathol 2014, 184:556-571

22. Presta M, Andres G, Leali D, Dell'Era P, Ronca R: Inflammatory cells and chemokines sustain FGF2-induced angiogenesis. Eur Cytokine Netw 2009, 20:39-50

23. Barrientos S, Stojadinovic O, Golinko MS, Brem H, Tomic-Canic M: Growth factors and cytokines in wound healing. Wound Repair Regen 2008, 16:585-601

24. Ishiguro $\mathrm{S}$, Akasaka $\mathrm{Y}$, Kiguchi $\mathrm{H}$, Suzuki $\mathrm{T}$, Imaizumi $\mathrm{R}$, Ishikawa Y, Ito K, Ishii T: Basic fibroblast growth factor induces down-regulation of alpha-smooth muscle actin and reduction of myofibroblast areas in open skin wounds. Wound Repair Regen 2009, $17: 617-625$

25. Gartland A, Mason-Savas A, Yang M, MacKay CA, Birnbaum MJ, Odgren PR: Septoclast deficiency accompanies postnatal growth plate chondrodysplasia in the toothless (tl) osteopetrotic, colony-stimulating factor-1 (CSF-1)-deficient rat and is partially responsive to CSF-1 injections. Am J Pathol 2009, 175:2668-2675
26. Sen V, Guzel A, Sen HS, Ece A, Uluca U, Soker S, Dogan E, Kaplan I, Deveci E: Preventive effects of dexmedetomidine on the liver in a rat model of acid-induced acute lung injury. Biomed Res Int 2014, 2014: 621827

27. Yao W, Firth AL, Sacks RS, Ogawa A, Auger WR, Fedullo PF, Madani MM, Lin GY, Sakakibara N, Thistlethwaite PA, Jamieson SW, Rubin LJ, Yuan JX: Identification of putative endothelial progenitor cells $(\mathrm{CD} 34+\mathrm{CD} 133+\mathrm{Flk}-1+)$ in endarterectomized tissue of patients with chronic thromboembolic pulmonary hypertension. Am J Physiol Lung Cell Mol Physiol 2009, 296: L870-L878

28. Kinoshita T, Ishikawa $\mathrm{Y}$, Arita M, Akishima-Fukasawa $\mathrm{Y}$, Fujita K, Inomata N, Suzuki T, Namiki A, Mikami T, Ikeda T, Yamazaki J, Ishii T, Akasaka Y: Antifibrotic response of cardiac fibroblasts in hypertensive hearts through enhanced TIMP-1 expression by basic fibroblast growth factor. Cardiovasc Pathol 2014, 23:92-100

29. Ribatti D, Nico B, Vacca A, Roncali L, Presta M: Endogenous and exogenous fibroblast growth factor-2 modulate wound healing in the chick embryo chorioallantoic membrane. Angiogenesis 1999, 3: 89-95

30. Kuzuya M, Kinsella JL: Induction of endothelial cell differentiation in vitro by fibroblast-derived soluble factors. Exp Cell Res 1994, 215: $310-318$

31. Hiraoka N, Allen E, Apel IJ, Gyetko MR, Weiss SJ: Matrix metalloproteinases regulate neovascularization by acting as pericellular fibrinolysins. Cell 1998, 95:365-377

32. Montesano R, Vassalli JD, Baird A, Guillemin R, Orci L: Basic fibroblast growth factor induces angiogenesis in vitro. Proc Natl Acad Sci U S A 1986, 83:7297-7301

33. Cebasek V, Erzen I, Vyhnal A, Janacek J, Ribaric S, Kubinova L: The estimation error of skeletal muscle capillary supply is significantly reduced by 3D method. Microvasc Res 2010, 79:40-46

34. Davis GE, Senger DR: Endothelial extracellular matrix: biosynthesis, remodeling, and functions during vascular morphogenesis and neovessel stabilization. Circ Res 2005, 97:1093-1107

35. Koh W, Stratman AN, Sacharidou A, Davis GE: In vitro three dimensional collagen matrix models of endothelial lumen formation during vasculogenesis and angiogenesis. Methods Enzymol 2008, 443: $83-101$

36. Liu Y, Senger DR: Matrix-specific activation of Src and Rho initiates capillary morphogenesis of endothelial cells. FASEB J 2004, 18: $457-468$

37. Newman AC, Nakatsu MN, Chou W, Gershon PD, Hughes CC: The requirement for fibroblasts in angiogenesis: fibroblast-derived matrix proteins are essential for endothelial cell lumen formation. Mol Biol Cell 2011, 22:3791-3800

38. Lee JG, Kay EP: FGF-2-mediated signal transduction during endothelial mesenchymal transformation in corneal endothelial cells. Exp Eye Res 2006, 83:1309-1316

39. Lee JG, Ko MK, Kay EP: Endothelial mesenchymal transformation mediated by IL-1beta-induced FGF-2 in corneal endothelial cells. Exp Eye Res 2012, 95:35-39

40. Ko MK, Kay EP: Regulatory role of FGF-2 on type I collagen expression during endothelial mesenchymal transformation. Invest Ophthalmol Vis Sci 2005, 46:4495-4503

41. Rakue H, Nakajima H, Katoh T, Usui M, Amemiya T, Miyagi M, Hara T, Tamura K, Sasame A, Naito Y, Nagai Y, Ibukiyama C: Low-dose basic fibroblast growth factor and vascular endothelial growth factor for angiogenesis in canine acute hindlimb insufficiency. Jpn Circ J 1998, 62:933-939

42. Tomanek RJ, Sandra A, Zheng W, Brock T, Bjercke RJ, Holifield JS: Vascular endothelial growth factor and basic fibroblast growth factor differentially modulate early postnatal coronary angiogenesis. Circ Res 2001, 88:1135-1141

43. Chaudhary LR, Avioli LV: Extracellular-signal regulated kinase signaling pathway mediates downregulation of type I procollagen gene 
expression by FGF-2, PDGF-BB, and okadaic acid in osteoblastic cells. J Cell Biochem 2000, 76:354-359

44. Chang L, Kaipainen A, Folkman J: Lymphangiogenesis new mechanisms. Ann N Y Acad Sci 2002, 979:111-119

45. Choi WW, Lewis MM, Lawson D, Yin-Goen Q, Birdsong GG, Cotsonis GA, Cohen C, Young AN: Angiogenic and lymphangiogenic microvessel density in breast carcinoma: correlation with clinicopathologic parameters and VEGF-family gene expression. Mod Pathol 2005, 18:143-152
46. Breiteneder-Geleff S, Soleiman A, Kowalski H, Horvat R, Amann G, Kriehuber E, Diem K, Weninger W, Tschachler E, Alitalo K, Kerjaschki D: Angiosarcomas express mixed endothelial phenotypes of blood and lymphatic capillaries: podoplanin as a specific marker for lymphatic endothelium. Am J Pathol 1999, 154: 385-394

47. Raica M, Cimpean AM, Ribatti D: The role of podoplanin in tumor progression and metastasis. Anticancer Res 2008, 28: 2997-3006 